\title{
Motivation, Incentives and Performance: An Interdisciplinary Review
}

\author{
Bruna Bruno $^{1} \&$ Marisa Faggini ${ }^{1} \&$ Anna Parziale ${ }^{2}$ \\ ${ }^{1}$ Department of Economics and Statistics, University of Salerno, Italy \\ ${ }^{2}$ Dipartimento di Scienze Giuridiche, University of Salerno, Italy \\ Correspondence: Bruna Bruno, Department of Economics and Statistics, University of Salerno, via Giovanni \\ Paolo II, 84084, Fisciano (SA), Italy. E-mail: brbruna@unisa.it
}

Received: August 24, 2017

Accepted: September 28, 2017

Online Published: November 20, 2017

doi:10.5539/ijbm.v12n12p29

URL: https://doi.org/10.5539/ijbm.v12n12p29

\begin{abstract}
This review aims to extend the application of economic knowledge to evidence supplied by other research areas on the relationships between incentives, motivation and performance. Six areas of investigation have been selected based on their potential contribution in addressing three issues relevant to economics. The first issue concerns the distinction between intrinsic and prosocial motivation; the second is the relationship between motivation and performance; the third relates to the existence of perverse effects of incentives on motivation, which can take the form of undermining or crowding-out effects. The results are discussed in terms of their implications for economic theory, showing that different mechanisms are at work under intrinsic or prosocial motivation, implying the need for different instruments to promote behaviors and associated performance. In terms of crowding-out effects, there is little evidence to support a perverse effect when incentives are offered before or during performance, whereas the psychological literature provides consolidated validation for the undermining effect. Economics can gain insights from other disciplines by employing their investigative tools and theoretical developments. A feature of particular interest for economics is gamification, that is, the use of game design elements (design of video games and similar games) in non-game contexts.
\end{abstract}

Keywords: intrinsic motivation, prosocial motivation, incentives, performance

JEL: D03, D64, J22

\section{Introduction}

Many disciplines are interested in the various forms of motivation as drivers of human behavior. Psychology offers a consolidated classification of motivation, mainly based on the distinction between intrinsic and extrinsic motivation.

Intrinsic motivation operates when individuals engage in behavior because they find the activity challenging and rewarding in itself and derive satisfaction in enhancing their competence in that specific task (Deci, 1971). Intrinsic motivation refers to doing something because it is inherently interesting or enjoyable, whereas extrinsic motivation refers to doing something because it leads to a separable outcome (Deci \& Ryan, 2000). In self-determination theory (SDT, Deci \& Ryan, 1985), intrinsically motivated activities provide the satisfaction of innate psychological needs - autonomy, competence and relatedness - the latter being a sense of belongingness and connectedness to the persons, group, or culture disseminating a goal (Deci \& Ryan, 2000). The interaction between intrinsic motivation and extrinsic incentives produces unintended effects because expected tangible rewards undermine intrinsic motivation (Deci et al., 1999).

The economics literature has imported the intrinsic motivation concept, focusing especially on the perverse effects of extrinsic rewards on intrinsic motivation. From the economic perspective, intrinsic motivation holds a problematic position because when it is crowded out by monetary incentives, the incentive mechanism fails to improve performance. Many attempts have been made to reconcile the maximization framework and certain observed behaviors performed without apparent material gain.

Beyond psychology and economics, other disciplines have investigated the relevance of intrinsic and extrinsic motivation. Engineering and informatics have investigated how humans interact with computers and technological structures that exert a greater effect in stimulating human interest. Medicine aims to promote desired behaviors, both from a preventive perspective and to address shortages in blood and organ donations. 
Marketing focuses its attention on the best way of attracting consumers to engage in repeat (purchase) behaviors by motivating and persuading them in many ways. Firms and public administrations try to select workers motivated to exert as much effort as possible. Often, these disciplines rely on psychological constructs, analyses and empirical evidence to search for answers to their (research) questions. Sometimes, economic theory and evidence are also used. Conversely, in investigating human choices and behavior, economics rarely imports results from other disciplines, still focusing on the maximizing agent pursuing his/her own welfare, mainly identified as goods availability.

The relevant question for economics is whether and how different types of motivation interact with economic incentives, individual choices, and their effects on performance. To provide an answer to this question, it would be useful to investigate how incentives, motivation and performance are analysed in other scientific areas and the main results of scientific research on this issue. The relevance of motivation highlighted in other scientific disciplines in which motivated behaviors are strictly necessary to explain observed behaviors can contribute to economics. Consequently, economics can gain new insights from different scientific perspectives, which propose alternative explanations concerning three issues related to incentives, motivation and performance.

The first issue relates to the distinction between intrinsic and pro-social motivation. In psychology, there are two different and separate strands of literature addressing intrinsic and prosocial motivation (Grant, 2008), whereas economics often treats the two as a single strand. Specifically, in the psychological literature, intrinsic motivation is based on interest and enjoyment, whereas effort exerted by pro-socially motivated individuals is based on a desire to benefit others (Ryan \& Connel, 1989). In management sciences, "intrinsic motivation involves fully autonomous self-regulation, whereas prosocial motivation is based on values other-oriented" (Grant \& Berry, 2011, p. 78). Nevertheless, it is possible for the two types of motivation to interact, reinforcing each other (Grant, 2008).

In economics, Benabou and Tirole (2006) modelled agents' prosocial or antisocial behavior as a mix of intrinsic, extrinsic and reputational motivation. Bowles and Polania Reyes (2012) use the term "social preferences", referring "to [such] motives as altruism, reciprocity, intrinsic pleasure in helping others and other motives that induce people to help others", thus adopting a broader definition because "moral, intrinsic, or other reasons unrelated to a concern for another's payoff often motivate people to help others" (p. 370). With this generalization, the authors seem to suggest that the distinction between intrapersonal and interpersonal phenomena is not meaningful for the economic analysis of the counterproductive effects of incentives. The implicit argument seems to be that for every motivational pressure, the resulting observed behavior is similar (Bruno, 2013). The rationale for the simplified concept used by economists lies in the focus on the self-interested behavior of a maximizing individual in opposition to all non-selfish behaviors. Ariely et al. (2009a) explicitly tested the detrimental effects of extrinsic incentives on pro-social behaviors and highlight those incentives "might interact with image motivation by diluting the signalling value of pro-social behavior" (p. 2), as predicted by Benabou and Tirole (2006). In the same vein, Goette et al. (2010) conclude that people are not influenced by the crowding-out effect when engaged in pro-social activities, suggesting that the perverse effects of incentives are relevant only when image concerns become important. On the other hand, intrinsic motivation has been found to strengthen the relationship between prosocial motivation and performance and productivity (Grant, 2008).

The second issue, which is preliminary to the third, concerns the relationship between motivation and choices and/or performance. The various types of motivation can be viewed as drivers for individual behavior, these being of different economic relevance depending on the reference framework. Thus, it is useful to distinguish between the role of motivation in the allocation problem and in the effort/performance problem.

In the allocation problem, a strong (intrinsic or prosocial) motivation can alter both individual preferences and the trade-off between alternative allocations defined by market prices. While different orientations are fully considered in economic analysis, motivational mark-ups on market prices may have interesting implications for many markets: intrinsic or prosocial motivational orientations result in some additional costs (or benefits) of goods, distancing market prices from attributed prices.

From the effort perspective, strong (intrinsic or prosocial) motivation is usually employed to explain activities performed without an apparent extrinsic reward. This is the area most investigated in economic research and many valuable contributions pay particular attention to the subsequent issue of the interaction between intrinsic and extrinsic rewards. Nevertheless, the analysis of mechanisms supporting both engagement in economic activities and its intensity should be a priority. This matter is relevant from the economic perspective because individuals with specific motivation can self-select themselves for specific activities, or gain better results 
compared to individuals without (intrinsic or prosocial) motivation. The self-selection of motivated individuals has been highlighted in various disciplines, from administration sciences to information systems research, with interesting results and interpretations, which can improve economic analysis. It is well known, for example, that self-selection has powerful implications for labour market results, both in terms of wage structure and job allocation. Advances in economic analysis can be derived from the systematization of this topic.

The third issue concerns the interaction between motivation and incentives, where extrinsic rewards or incentives have an effect on behavior only if it is driven by extrinsic motivation. For intrinsically and pro-socially motivated behaviors, the open question is whether they are crowded out or undermined by extrinsic rewards. The psychological literature contains many studies on the effects of rewards on intrinsically motivated behaviors, thoroughly investigated by Deci et al. (1999). The "undermining effect" underlines that for intrinsically motivated behavior, extrinsic rewards may have a counterproductive effect when they are removed. Economics has imported the results of psychological studies, but with some relevant differences (Bruno, 2013). The first difference is the definition of intrinsic motivation, which is strictly linked to the feeling of being able and competent, whereas in economic studies it is often extended to prosocial behavior. The second difference is in the timing of crowding out (undermining in psychological research), where the crowding-out phenomenon refers to the reduction in performance when incentives are offered to participants before or during performance. In contrast, psychological research highlights that performance worsens after incentives are removed. This difference is often considered irrelevant in comparing psychological and economic analyses, creating difficulties when discussing results from the two areas of research (Festrè \& Garroust, 2015). In greater detail, Frey and Jegen (2001) used psychological research to explain why extrinsic rewards may have a counterproductive effect when self-esteem and self-determination are perceived by individuals as controlling. Benabou and Tirole (2006) have described the crowding out that arises in an asymmetric information setting, in which the more informed principal signals a difficult task or lower ability through extrinsic rewards.

\section{Review Strategy}

The first aim of this review is to extend the application of economic knowledge to evidence supplied by other research areas on the functioning of incentives when intrinsic motivation is in place and to classify proposed explanations concerning the above issues. This will enable the selection of more relevant responses for the economics and identify their correct placement in the economic framework.

To take a unique approach to the above issues, the paper reviews some discussions of intrinsic motivation from different areas of research. The focus is on areas other than economics and psychology, in which research has been consolidated by Deci et al. (1999) and Bowles and Polania-Reyes (2012), for example, who have reviewed respectively psychological and economic research. Furthermore, a detailed comparison between economic and psychology on this topic can be found in Festrè and Garroust (2015). Accordingly, we review some topics in which motivation has been highlighted as relevant in the scientific literature, comparing methodologies and results. We have selected topics according to their potential contribution to the three issues raised in the introduction. The topics identified present a strand of sectoral literature in which researchers have explicitly applied SDT and/or directly have measured intrinsic motivation and/or tested the undermining/crowding-out effect of incentives. Following this approach, we identify six topics studying the relationships between motivation, incentives and performance/choices: information technology, health, entrepreneurship, consumption, public administration, the environment and volunteering.

For each argument, after a brief definition of the phenomenon as proposed by the scientific literature, we propose three steps of analysis. In the first step, to provide evidence of the distinctions between intrinsic motivation and pro-social motivation, detailed attention is paid to the measurement of motivation. In this area, studies vary widely, in terms of both the object of study and the methodology. Therefore, the empirical evidence concerning motivation is discussed for each area, distinguishing between evidence supporting self-assessed motivation and other results that authors claim demonstrate the existence of intrinsic or pro-social (inferred) motivation.

Thus, we aim to answer the following questions: Is intrinsically motivated behavior distinguishable from pro-socially motivated behavior when dealing with economic problems? Is it a useful distinction? It should be noted that intrinsically motivated behavior is closer to the individualist optimizing agent pursuing his/her own welfare, whereas pro-social motivation implies a more complex interaction between an individual's objective function and others" welfare, according a place to an "other-regarding" preference structure (Fehr \& Fishbacker, 2002). It is always possible that an intrinsically motivated behavior may produce positive externalities for other individuals and therefore have an effect on others' welfare, but it should be considered an unintended effect without any return for the individual's own welfare. Pro-social motivation leads to individuals intentionally 
pursuing their own welfare by improving others' welfare. From a theoretical point of view, stimulating pro-social motivation has a direct impact on the individual's performance and on collective well-being, whereas enabling intrinsic motivation only affects individual satisfaction.

The second step explores the relationship between motivation and choices and/or performance. Although economics is primarily interested in the relationship between incentives and performance, contributions from psychology suggest that behavior and performance are driven by intrinsic or extrinsic motivation. Incentives have an effect on performance and choices through enhancing or undermining motivation. It is essential to examine how the relationship between motivation and performance/choices has been investigated and assessed, establishing the existence of a causal link that goes from incentives to motivation and from motivation to performance. Two kinds of evidence can support the existence of a relationship between motivation and performance or choices: i) evidence on self-selection of individuals endowed with intrinsic or pro-social motivation in specific tasks, organizations or activities; ii) correlations between intrinsic or pro-social motivation and the qualitative/quantitative aspects of associated performance. For each topic, we review, when available, issues concerning the self-selection of motivated individuals in specific tasks or activities and whether the scientific literature highlights a positive relationship between motivation and performance.

In the third step, the relationship between motivation and incentives in different areas of investigation is analysed to highlight the kind of relationship that exists and to verify how the undermining or crowding-effect is effectively spread across behaviors.

Specifically, sections 2-7 analyse the six topics described above and section 8 is devoted to some cross-cutting themes. Section 9 discusses the results and their contributions to economics.

\section{Information Technology}

\subsection{Definitions}

Information technology offers new challenges and insights to both producers and consumers. On the supply side, large producers often work together with crowdsourcing contributors.

Open source software (OSS) is defined as software in which users can inspect the source code, modify it and redistribute modified or unmodified versions for others to use (von Krogh et al., 2012). A growing bulk of scientific literature, from different disciplines, is interested in OSS, investigating innovation patterns, organizational schemes and other issues. In developing OSS, some contributors are unpaid volunteers, whereas others are paid developers. Moreover, developers also devolve most property rights to the public, including the right to use, redistribute and modify the software (Hars \& Ou, 2005). We extract from the literature only the analyses concerning motivational aspects. Note that motivation of OSS developers is sometimes also classified as a pro-social motivation that stimulates individuals to produce a public good of two different orders: the functionality and quality of the programs and the openness of the code itself (Osterloh \& Rota, 2007).

On the demand side, information technology is the ideal framework for the development of entertainment products. Media, social networks and massively multiplayer online games (MMOG) are part of life today and have economic and psychological relevance. In terms of games, an interesting question is what drives and makes games perpetually interesting. In 2004, Richard Bartle identified several types of gamers, based on their motivation. Following his seminal book, psychological research on video games, which had previously focused on the potential negative effects of games, empirically investigated players' motivation. Yee (2006) employed factor analysis to select three components, achievement, socializing and immersion. Przybylski et al. (2010) and Tamborini et al. (2010) specifically tested SDT to show the role of intrinsic motivation.

An interesting evolution of the motivational relevance of games and video games is their application as instruments to promote (other) desired behaviors. Games can be used to promote children's dietary outcomes (Baranowski et al., 2003; see also 3.3.2) or other desired performance. In these applications, the enjoyment produced by the game is used to enhance the attention paid to a message promoting another behavior. According to social cognitive theory and the elaboration likelihood model (Petty \& Cacioppo, 2012); enhancing motivation focuses attention on specific behavioral changes (Baranowski et al., 2008).

Researchers studying human-computer interaction ( $\mathrm{HCI}$ ) have recently focused attention on a new phenomenon they call "gamification". As defined by Deterding et al. (2011), "gamification" is the use of game design elements in non-game contexts, in which gaming and games - in contrast to playing and toys - are characterized by explicit rule systems. Huotari and Hamari (2011) define "gamification" as a "service packaging where a core service is enhanced by a rules-based service system that provides feedback and interaction mechanisms to the user with an aim to facilitate and support the users' overall value creation" (p. 3). Gamification has 
psychological and behavioral outcomes, which have been studied in numerous contexts, ranging from education/learning, to health, work and organizations (Hamari et al., 2014). Most psychological outcomes are yet confined to the area of education and learning, in which the psychological literature still offers support for the role of intrinsic motivation. In extending our knowledge of intrinsic motivation, it is essential to explore how motivation works in different contexts.

\subsection{Measurements}

\subsubsection{Self-assessed motivation}

Hars and Ou (2002) asked specific questions concerning motivation to participate in OSS development. In their results "while internal factors such as intrinsic motivation ... play a role, external factors have greater weight". In their survey, extrinsic motivation was found to be more frequent, with major prominence in terms of human capital building and self-marketing, especially among salaried and contract programmers, whereas hobbyists and students are more intrinsically motivated. Using a web-based survey, Lakhani and Wolf (2003) investigated the motivation of developers by asking them how creative they felt when working on a project, finding creativity to be the strongest and most pervasive driver. Roberts et al. (2006) measured the motivation of OSS participants in Apache projects in terms of aspects of the task itself using four-scale items in a web-based survey. Budhathoki and Haythornthwaite (2012) developed a classification of 44 items (intrinsic and extrinsic), on a seven-point Likert scale, to measure motivational factors related to contributing to the wiki OpenStreetMap, a site for voluntary geographic information. The authors found that those more engaged in contributing to the site reported enjoyment and self-efficacy as significant motivating factors.

Tamborini et al. (2010) investigated media enjoyment, employing constructs and relations of SDT. They show that variance in media enjoyment in a video game experiment can be explained by autonomy, competence and relatedness. Meckler et al. (2013) used the Intrinsic Motivation Inventory (IMI) to measure the effects of points a basic element of gamification - on intrinsic motivation and performance. They found that some elements of gamification (points and a meaningful frame) enhance participants' intrinsic motivation. Ryan et al. (2006) developed an empirical application of SDT to on-line and off-line video games, measuring game enjoyment using four items from the IMI. They found that game enjoyment is significantly related to the measures of autonomy, competence and relatedness in terms of satisfaction of needs. Witt et al. (2011) suggest that intrinsic motivation plays a role when gamification is applied to innovation management, but their sample was very small.

\subsubsection{Inferred Motivation}

Alexy and Leitner (2011) combined an online survey with a scenario experiment to capture intrinsic motivation through the existence of a norm for or against payments for each individual participating in the experiment.

\subsection{Motivation, Performance and Choice}

Lerner and Tirole (2002) study OOS in the economic perspective, paying major attention to problems related to industrial organization. Nevertheless, the authors also include a section on programmers' motivation, underlining the benefits and costs of developing OSS. To shed light on how mainstreaming economic theory can explain many of the features of OSS projects, considerable attention is given to the role of delayed benefits, career concerns and ego gratification incentives that stem from peer recognition. Both motives are grouped in a signalling incentive and discussed in the signalling framework. Nevertheless, among the benefits, the authors also list some immediate benefits arising from competence accumulation and "fun". Other studies give more prominence to these immediate benefits. Intrinsic motivation, in the Deci definition, is explicitly considered as the motivation driving developers' behaviors because they enjoy writing codes, feeling competent and having fun programming. Other intrinsic factors identified are altruism and community identification. In contrast, extrinsic motivation concerns the expectation of future rewards and specific personal needs (Hars \& Ou, 2005). Osterloth and Rota (2005) explain that the co-existence of intrinsic and extrinsic motivation is vital to the success of OSS because first- and second-order social dilemmas are better solved than in other projects. The most comprehensive discussion of developers' motivation is in David and Shapiro (2008). A more recent review is provided by Carpenter (2013).

In the game-player area, enjoyment can be viewed as a conceptualization of intrinsic motivation. To develop this analysis, it is crucial and appropriate to study online game-player behavior. Intrinsic motivation plays a very significant role in predicting intentions to play online games (Mehri, 2016; Wu \& Liu, 2007). Przybylski et al. (2010) specifically test SDT to show that competence and autonomy, as components of intrinsic motivation, are significant in determining future play and more hours of play. 


\section{Health}

\subsection{Definitions}

There is a two-way interaction between health and motivation. On the one hand, many studies have investigated how individuals can be motivated to adopt healthy behaviors. On the other hand, the need for blood and organ donations has stimulated investigations on how to promote these behaviors.

The most important difference is in the recipient of the benefits: smoking cessation, physical activity aimed at weight loss, adherence to medication, screening and so on have direct benefits for those engaging in such behaviors. In contrast, blood and organ donations are better classified in the category of pro-social behaviors because the beneficiaries are not those engaging in the behavior.

Concerning healthy behaviors, a second relevant difference, suggested by Charness and Gneezy (2009), lies in the conventionally accepted "quality" of the behaviors: different results are observed in relation to the acquisition of good habits (e.g. gym attendance) versus the elimination of bad habits (e.g. smoking). To the best of our knowledge, no studies have directly investigated the motivation to cease unhealthy behavior, such as smoking, but many studies have analysed the effects of incentives on smoking cessation, showing that these are efficacious for promoting smoking abstinence. Participation in a cessation programme is probably intrinsically motivated, with a view to attaining a better lifestyle, but it seems difficult to classify this motivation in terms of the enjoyment characteristics highlighted by Deci. The use of incentives to modify bad habits is generally tested with reference to a different theoretical background, such as contingency management theory and operant learning, which predict that behaviors producing rewards tend to be repeated (reinforcement), while behavior resulting in punishments tend to be repeated less frequently (Jeffery, 2012). The meta-analysis by Ng et al. (2012) considers many health behaviors, such as physical activity, diabetes care, abstinence from tobacco and weight control.

In terms of pro-social behavior related to others' health, since the seminal paper of Titmuss (1970) on paying for blood donations, many researchers have tried to verify the hypothesis that payment will reduce blood quality, undermining the altruistic motivation for blood donation. The interest in various research fields has widened to encompass both the quantity and quality of blood donations and test if the crowding-out effect occurs when payments are offered.

\subsection{Measurements}

\subsubsection{Self-Assessed Motivation}

Liking vegetables is a healthy habit, which is difficult to teach to children. In an experiment conducted by Cooke et al. (2011), liking for and intake of vegetables were assessed in a free-choice pre-intervention consumption task. In another investigation by Puente and Anshel (2010), a battery of questions on motivation, competence and enjoyment were completed before engaging participants in fitness exercises.

The motivation for donating blood has rarely been investigated. Glynn et al. (2002) analysed the results from the 1998 REDS Survey of US donors and found that the major reasons to for donating were altruism and awareness of the need for blood. Pentecost et al. (2107) measured intrinsic motivation on a six-point scale using three questions strongly associated with the narrow definition of intrinsic motivation (the activity is interesting, pleasant and fun).

\subsubsection{Inferred Motivation}

A field experiment conducted by Charness and Gneezy (2009) on gym attendance used previous attendance as a measure of intrinsic motivation: in this case, the hypothesis was that someone visiting the gym is intrinsically motivated to do so. The authors did not consider the case of extrinsic motivation related to previous gym attendance, such as medical prescription or athletic training for college competitions, which could provide an explanation for a reinforcing effect as opposed to an undermining effect. As Della Vigna and Malmendier (2006) show, consumers who choose a monthly contract for gym attendance are more likely to stay enrolled compared to those committing for a year, even if the former pay higher fees. The authors explain this counterintuitive evidence by the overconfidence of those choosing the annual fee: they try to commit themselves by paying for a longer subscription, but they have lower intrinsic motivation gym and "overestimate their future self-control or their future efficiency in pursuing costly activities (p. 695). Extrinsically motivated individuals need monetary reinforcements to increase their frequency of gym attendance.

In the field of blood donations, Upton (1973) used previous blood donation as a measure of intrinsic motivation to donate blood, finding opposite patterns between the group of individuals who had donated blood before and 
the group of those who never donated. However, according to Goette et al. (2010), the studies conducted by Upton suffer from a self-selection problem because the compensation was announced in the recruitment phase of the experiment.

\subsection{Motivation, Performance and Choice}

\subsubsection{Self-Selection}

Cahill and Pereira (2011) argue that there is a self-selection problem in smoking programmes because individuals participating in a cessation program in which material rewards are supplied may be motivated differently from those who sign up to more conventional methods. In Charness and Gneezy's (2009) study, without a direct assessment of the intrinsic motivation to attend gym among the participants, the results could be attributed to the self-selection of extrinsically motivated individuals in the experiment: students enrolled in experiments may well pursue monetary payments and be more extrinsically motivated than those who do not participate. This implies a trend towards extrinsic motivation, even if participants could be selected in terms of their intrinsic motivation to attend gym.

\subsubsection{Motivation and Performance}

$\mathrm{Ng}$ et al. (2012) found positive positive relations of psychological need satisfaction and autonomous motivation to beneficial health outcomes, analysing 184 studies concerning health behaviors; however, they stress that the relationships are cross-sectional associations and cannot be used to infer causality.

It should be noted that many studies have investigated the relationship between healthy outcomes and games. The idea is that by employing video games, one can provide a channel for delivering health behavior-changing experiences and messages in an engaging and entertaining format (Baranowski et al., 2008). Although these studies do not directly test the motivation for improving health, they can be considered good proxies for the relationship between enjoyment as a motivation for games and performance (cf. section 2 above), in which performance is not the task itself (gaming), but rather the associated (healthy) behavior.

For Puente and Anshel (2010), individuals who exercise due to more self-determined reasons tend to enjoy the activity more and engage in the activity more consistently and for a longer period of time. In Teixeira et al.'s (2012) review, the conclusion is that intrinsic motivation is more predictive of long-term adherence to exercise. Pentecost et al. (2017) show a positive relationship between intrinsic motivation and intention to donate blood.

\subsection{Motivation and incentives}

\subsubsection{Undermining}

Promberg and Marteau classify the experiments by Cooke et al. (2011) and Charness and Gneezy (2009) as tests of undermining. In the first study, Cooke et al. (2011) measured the effect of rewards among children on vegetable intake up to three months after intervention, finding that children who received tangible rewards liked the vegetables equally or more, even after the incentive was removed. The same holds for gym attendance studied by Charness and Gneezy (2009), who undertook measurements before and after monetary reward and found increased performances. Studies evaluating the use of financial incentives to promote weight control show that they are an efficient means of supporting both the initial change and its maintenance (Jeffery, 2012). However, all the existing research has been done with volunteers interested in weight loss and it could be assumed that the participants are already intrinsically motivated to lose weight. At the same time, weight loss behaviors produce reductions in other sources of intrinsic pleasure, such as the pleasure of eating. Unfortunately, little evidence is available on the measurement of this motivation for weight loss. In a meta-analysis conducted by $\mathrm{Ng}$ et al. (2012), the authors note that few studies have followed patients after the intervention. Promberger and Marteau (2013) conclude that evidence on smoking cessation does not provide support for crowding-out and undermining effects.

In the field of blood donations, according to Niza et al. (2013), "no studies on blood donations provide data on the likelihood of donating after incentives are withdrawn" (p. 942). Goette et al. (2010) list only one experiment testing the undermining hypothesis by Goette and Stutzer (2008): following donors up to 18 months after the experiment, they found no effect on subsequent donations.

\subsubsection{Crowding Out}

The issue most investigated among blood donors is the effect of monetary/non-monetary incentives on blood supply. Although studies have not investigated the motivation for donating blood, common sense would argue that findings supporting the crowding-out/undermining effect of incentives on the quality/quantity of blood donations should also support the existence of a pro-social/intrinsic motivation. Glynn et al. (2003) studied 
attitudes towards incentives through an anonymous survey. Their findings suggest that up to $7-9 \%$ of donors would be discouraged by compensatory incentives. Moreover, in terms of blood safety, cash compensation could negatively affect the blood supply, whereas the use of non-monetary incentives would probably not exert a negative impact. Mellstrom and Johannesson (2008) found gender differences in the reaction to monetary incentives, identifying a significant crowding-out effect for women. Niza et al. (2013) performed a meta-analysis on the relationship between incentives and blood donations, excluding studies in which rewards of little or no monetary value (such as certificates or badges) were offered, finding that financial incentives have no effect on the quantity of blood. As for the quality of blood, they found only two studies matching the inclusion criteria, with no evidence supporting poorer quality when financial incentives are in place. Lacetera et al.'s (2013) survey found considerable evidence of a crowding-out effect in blood donation, but emphasized that such evidence is provided by uncontrolled studies with non-random samples, surveys and laboratory evidence, which are unusual instruments on which to base health policy. Randomized field trials are considered better instruments and the recent results give opposite results.

\section{Entrepreneurship}

\subsection{Definitions}

In management sciences, researchers have found evidence for entrepreneurship motivation that cannot be linked solely to the profit motive. Hayter (2011), who lists, among others, types of motivation that fit both Deci's definition and pro-social motivation, provides a synthetic summary of the entrepreneurial motivation literature. In the first category, one can include "challenge" and "need for personal development and learning", "self-realization", "independence" and "creation of new ideas", which correspond to satisfaction in enhancing one's competence and the perception of the challenge and reward in the activity itself. In the second category are the "contribution to the community" and the "dissemination of work". Other motivations are extrinsic.

The sociological sciences have investigated "priorities in scientific discovery", ascribing two main types of motivation to scientific activity: the extrinsic recognition awarded by the scientific community (Merton, 1957, 1973) and the intrinsic satisfaction of solving a "puzzle" through doing research (Hagstrom, 1965). Recent research has focused on the motivation that drives academics engaged in commercial activities or academic entrepreneurship (spinoff companies). Recently, Iorio et al. (2017) have shown an additional motivation that they term "mission motivation" to describe academics engaging in knowledge transfer activities, representing the scientist's contribution to promoting the social role of universities, which most closely fits the definition of pro-social motivation.

\subsection{Measurements}

\subsubsection{Self-assessed Motivation}

Kuratko et al. (1997) interviewed entrepreneurs concerning their motivation using 16 goal statements rated on their relevance. Through factor analysis, they show the existence of intrinsic goals, such as recognition, challenge, excitement, growth and accomplishment, together with extrinsic goals. Cassar (2007) measured the reasons for engaging in ventures through 18 items rated on a five-point scale, grouped using factor analysis. They found that "money is not the only, or even the most important, motive for entrepreneurs' decision to start new high-growth ventures" (p. 104). Hessels et al. (2008) investigated the independence motivation assessed through the Global Entrepreneurship Monitor (GEM) Adult Population Survey (2005). It is interesting to note that high-technology entrepreneurs are especially characterized by motives concerning independence, challenge and the dissemination of their work (Corman et al., 1988; Hessels et al., 2008; Wiklund et al., 2003), as stressed in section 2 .

Lam (2011) measured the intrinsic satisfaction derived from the fulfilment of intellectual curiosity through individual interviews and on-line questionnaires with the objective of examining scientists' motivation for pursuing commercial activities. Hayter (2011) examined motivation and definitions of success among nascent academic entrepreneurs, finding that both financial gains and intrinsic motivation are relevant to academic entrepreneurship. Iorio et al. (2017) used factor analysis on 16 items referring to academics' motivation to engage with the non-academic environment, measured on a four-point Likert scale.

\subsection{Motivation, Performance and Choices}

Analysis of the relationships between entrepreneurial motives and economic performance shows that economic motives for entrepreneurial career reasons do change over time and that independence is the most important factor in explaining the career choices of nascent entrepreneurs, but is negatively associated with the intended and achieved employment growth of firms, suggesting an inverse relationship (Cassar, 2007). 
Lam (2011) analysed scientists' motivation in pursuing commercial activities. She found that intrinsic motivation, related to autonomy and "puzzle-solving" intellectual curiosity, is of relevance for those who believe that science-business collaboration is fundamental for knowledge exploitation; in contrast, scientists who are extrinsically motivated by financial rewards and reputational concerns believe that academia and industry should be distinct. Respondents in Hayter's (2011) study indicated, inter alia, that some forms of pro-social motivation enhance the relevance and quality of their university, the public service mission of their institution (see also section on Public Administration) and job creation opportunities for individuals. Iorio et al.'s (2017) study produced a counterintuitive result in showing a positive relationship between pro-social motivation and knowledge-transfer activities, but no significant role for the learning motivation, which includes interest in research, competence complementarities and the search for research insights, all closer to the strong definition of intrinsic motivation.

\subsection{Motivation and incentives}

Analysing patentable subject matter, Atiq (2014) highlights that laws of nature, natural phenomena and abstract ideas are implicitly excluded from the "Patent Act". According to the author, by introducing monetary incentives in the form of patents in the domain of scientific enterprise could crowd out intrinsic motivation, such as the love of knowledge and the desire to exercise intellectual faculties.

\section{Consumption}

\subsection{Definitions}

Consumer research focuses on how consumers choose and use available means to pursue their own goals. The consumption experience - especially on-line purchasing - is considered a mix of extrinsic and intrinsic values: the experiential value of purchasing includes enjoyment and playfulness, and intrinsic value is derived from the "appreciation of an experience for its own sake, apart from any other consequence that may result" (Holbrook, 1994, p. 40). In this area, researchers have developed an Experiential Value Scale (EVS) to measure the benefits derived from playfulness, aesthetics, customer "return on investment" and service excellence, employing psychometric measures (Mathwick et al., 2001). Although rarely associated with Deci's definition of intrinsic motivation, which usually concerns tasks, to be completed, intrinsic value is considered important for loyalty and customers' repeat purchase intentions (Chiu et al., 2014). It is, therefore, a good candidate for testing the relationship between motivation, incentives and performance from a broader perspective.

An evolving style of consumption has recently emerged, based on new opportunities fostered by information technology. The sharing economy is an emerging economic-technological phenomenon, characterized as being driven by the obligation to do good for other people and for the environment, such as sharing, helping others and engaging in sustainable behavior (Hamari et al., 2015; Prothero et al., 2011). Collaborative consumption is a temporary agreement on the use of a good or service with flexible and temporary co-ownership (Bruno et al., 2016). Bardi and Eckhardt (2012) refer to the latter characteristic as "access-based consumption", highlighting that it represents the evolution of a consumption style in which ownership is no longer the ultimate expression of consumer desire (Chen, 2009). Different forms of motivation drive collaborative consumption: Hamari et al. (2015) investigated the enjoyment derived from sharing as an intrinsic motivation and the pro-environment motivation associated with saving resources. Benkler (2004) argues that there is "some form of social-psychological motivation that is neither fungible with money nor simply cumulative with it" (p. 326). Pais and Provasi (2015), who suggest that the sharing economy can re-embed economic relations in social relations, also stress the social aspect of collaborative consumption. Similar to collaborative consumption, consumer-to-consumer reselling auctions can imply intrinsic motivation (Chu, 2013). Auction activities and ongoing hobby-type searches are the most frequently mentioned motivations for online browsing, with positive surprise and excitement being major benefits of auction sites (Wolfinbarger \& Gilly, 2001).

\subsection{Measurements}

\subsubsection{Self-assessed Motivation}

Anghelcev's (2015) study measured the intrinsic motivation in promoting a favourite brand (Apple computer vs PC) using a seven-point Likert scale. Kivetz (2003) measured interest in specific task, again employing a seven-point scale. Koufaris (2002) measured enjoyment through four questions. Poch and Martin (2014) measured altruism using a self-report scale.

Hamari et al. (2015) used psychometric measures to test intrinsic motivation, both in terms of enjoyment derived from the activity itself and as concern for sustainability. They collected responses from registered users of Sharetribe to verify the influence of different motivational aspects on attitudes towards collaborative 
consumption and on actual behavior.

\subsection{Motivation, Choices and Performance}

Koufaris (2002) shows that both enjoyment of the shopping experience and the perceived usefulness of the website are important for a new customer's intention to return. Ahn et al. (2007) demonstrate that playfulness plays an important role in enhancing users' attitudes and behavioral intention to use a site. The study by Poch and Martin (2014) focused on user-generated video content promoting brands. They found a significant effect of altruism on positive user-generated branded video content.

According to Hamari et al. (2015), the perceived sustainability of collaborative consumption significantly predicts attitudes to shared consumption but not concrete behavior. Nevertheless, the intrinsic enjoyment derived from sharing activities has a significant effect on both attitudes towards collaborative consumption and the behavioral intention to participate in a sharing economy.

\subsection{Motivation and Incentives}

Anghelcev's (2015) experiment compared recommendations promoting the Apple products, written by two groups of students, and found that the group that was rewarded wrote shorter recommendations. Conversely, Kivetz (2003) hypothesized that intrinsically motivated individuals have lower expectations of rewards and, in a risky choice, were less likely to prefer the sure-small reward compared to individuals who disliked this activity.

\section{Public Administration}

\subsection{Definition}

In the administrative sciences, public service motivation (PSM) is defined as "an individual's predisposition to respond to motives grounded primarily or uniquely in public institutions and organizations" (Perry \& Wise, 1990, p. 368). This motivation differs from the narrow definition of intrinsic motivation, which is rooted in the pleasure of doing something and feeling competent in the task, as PSM is a pro-social motivation, for which meanings and purposes matter (Perry et al., 2010). In contrast, Vandenabeele (2007) explicitly links PSM to SDT, arguing that institutions can foster intrinsic motivation and public servants' performance by responding to the individual psychological needs of relatedness, competence and autonomy. A recent review is provided by Ritz et al. (2016).

\subsection{Measurements}

\subsubsection{Self-assessed Motivation}

Perry (1996) developed the first measurement scale in this area using four dimensions with many Likert-type items, which many subsequent studies adopted, also in the survey-based version (e.g. Liu et al., 2008, for Chinese workers). The author tested the measurements through confirmatory factor analysis.

Brewer and Selden (1998) used answers to questions about organizations' values and commitment to study the relationship between PSM and prosocial behavior associated with whistle blowing. Lyons et al. (2006) measured both intrinsic values and altruistic values in public and private organizations, finding no significant difference between the two sectors.

Other studies in public administration have used questionnaires and multivariate analyses (Houston, 2000; Kim, 2005). Grant (2008) measured both prosocial and intrinsic motivation among firefighters and fundraising callers at a public university using the self-regulation scales developed by Ryan and Connell (1989). Bertelli (2006) estimated a latent variable, representing both intrinsic motivation and the "warm glow" of altruism, employing item response theory and measuring six items using five-point agreement scales. Alonso and Lewis (2001) analysed data from two large surveys of federal employees, selecting "service to others" as the variable representing public service motivation.

Park et al. (2016) investigated the relationship between pay-for-performance schemes and happiness in the public and private sectors, finding that pay for performance has a stronger negative effect on happiness in the public sector.

\subsubsection{Inferred Motivation}

Georgellis et al. (2011) considered self-reported satisfaction with work itself as a proxy for workers' motivation. Their self-report data show compatibility with both an intrinsic pleasure in doing a specific task and the pro-social motivation to pursue the public interest, as well as enjoying helping others through public work. This measure assumes a positive correlation between intrinsic motivation (or pro-social motivation) and satisfaction, as postulated in SDT (Ryan \& Deci, 2000). Grant (2008) shows that intrinsic motivation, but not job satisfaction, interacts with pro-social motivation to predict performance. The relationship between intrinsic motivation and 
satisfaction should be carefully considered.

Gregg et al. (2011) used unpaid overtime as measure of pro-social behavior, including a number of controls for career issues to exclude the possibility that individuals do unpaid overtime hoping for higher remuneration or promotion in the future. They also excluded that unpaid overtime is the result of a gift-exchange for other benefits. They show that individuals switching sectors (profit/non-profit) do not change behavior in supplying unpaid overtime hours.

\subsection{Motivation, Choices and Performance}

Individuals who are attracted to public service are likely to self-select into public organizations (Perry, 2000). Delgaauw and Dur (2008) provide a theoretical explanation for the selection of motivated workers. In their model, the optimal strategy for a public agency is to hire the economy's laziest workers with weaker incentives than the market sector does; in this way, motivated workers can be hired at lower wages. The basic assumption is that lazy or regular workers must be paid as in the private sector, whereas motivated workers accept lower wages. This result occurs if the public agency has a cost-minimizing strategy, not a social welfare strategy.

Crewson (1997) used the ranking of different aspects of jobs stated by employees to measure the relevance of motivation in the private and public sectors. The results show that "profit-seeking firms are likely to be dominated by economic-oriented employees while public-service organizations, both public and nonprofit, are likely to be dominated by service oriented employees" (p. 515).

Delgaauw and Dur (2008) assume that regular workers move from the public sector to the private sector, whereas lazy and motivated workers move in the opposite direction. In terms of motivated workers, Georgellis et al. (2011), who show that "higher predicted satisfaction with the nature of the work itself... increases individuals' propensity to make the transition from the private into the public sector (p. 474), confirm this evidence. Gregg et al. (2011) support the selection of individuals into different sectors according their pro-social motivation (measured by unpaid overtime hours). They show that individuals switching from non-profit sectors (as a sum of non-profit and public sectors) to for-profit sectors do less unpaid overtime than those who stay. In the same way, individuals switching from profit to non-profit do more unpaid overtime than those who stay.

According to Perry and Wise (1990), in public organizations, public service motivation is positively related to individual performance. When assessing the relationship between motivation and performance in the public sector, the main problem is the definition and measurement of performance itself. It could be argued that if problems of measurement of performance are solved, the same kinds of incentive schemes applied in the private sector could be extended to the public sector (Festré \& Garrouste, 2008). Alonso and Lewis (2001) used federal grades and performance ratings as indicators of "long run performance", admitting "grades and ratings do not perfectly reflect performance" (p. 366). Grant (2008) analysed the interaction between pro-social motivation and intrinsic motivation in relation to performance, showing that pro-social motivation is positively associated with overtime hours when intrinsic motivation is high, whereas it is negatively associated when intrinsic motivation is low.

\subsection{Motivation and Incentives}

\subsubsection{Undermining}

Georgellis et al. (2011) indirectly tested the effects of incentives on motivation. They show that the higher the intrinsic satisfaction with work itself, the higher the likelihood of moving into public jobs, whereas the higher the extrinsic satisfaction (with hours of work, job security and pay), the lower the likelihood of moving into public jobs. Some considerations follow from this. First, the move from the private to the public sector is not related to performance and therefore it is not possible to predict any impact of incentives on performance based on this evidence. Second, from the data, we cannot observe any variations in intrinsic motivation "due" to the extrinsic incentives. Third, the authors use the estimated differential of satisfaction prior to and after each transition and conclude that a higher predicted satisfaction differential with respect to extrinsic values decreases the likelihood of moving into the public sector. This result only shows that workers expecting higher satisfaction with pay (or working hours) are less like to move to the public sector and workers expecting lower satisfaction with pay (or working hours) are more likely to move to the public sector. As a whole, people with low interest in extrinsic rewards move to the public sector also if they expect little satisfaction in terms of pay, which is coherent with PSM. On the other hand, those expecting higher satisfaction with pay do not move to the public sector. This is puzzling because it can be interpreted in two different ways: a) as in Georgellis et al. (2011), high extrinsic rewards reduce the interest in public service because the agents have reputational concerns and wish to appear pro-social/altruistic; b) workers expecting higher satisfaction with wages put much more emphasis on wages and 
decide to stay because the expectation is not sufficiently met. The interpretation according to a) needs to show that intrinsic motives are reduced by higher extrinsic expectations. The interpretation according to $b$ ) should compare both expectations, i.e. those in the public and private sectors.

\subsubsection{Crowding Out}

Bertelli (2006) tested the motivation crowding-out effect by comparing groups of employees in the same institution with different levels of intrinsic motivation. As he points out, it is "impossible to examine the change in intrinsic motivation exhibited by an employee before and after the implementation of extrinsic incentives without a pre-post experimental design". The study shows that employees with a low endowment of intrinsic motivation develop a belief of interest in their work when rewarded, whereas highly motivated individuals reveal beliefs of monetary motivation for work when rewarded. For the author, this is consistent with crowding out, but he highlights the lack of control variables, such as education and time spent in the position. Notably, the highly motivated individuals are in supervisory positions, whereas those with low motivation are subordinates and thus a self-selection problem could exist.

Franck and Rosenthal (2006) show that financial incentives can yield productivity improvements for some areas of the public sector: the evidence is strongest for civil servants and teachers, but relatively weak for healthcare workers.

\section{Environment and Volunteering}

\subsection{Definitions}

Environmental psychology offers a wide range of studies on the types of motivation driving pro-environment behaviors. Many studies have investigated the best way of promoting environmentally responsible behaviors through material incentives or disincentives (Geller, 1989). Altruism is considered one of the drivers of pro-environmental behaviors, but intrinsic satisfaction and the desire for growing competence are also shown to be relevant in environmental behaviors (De Young, 2000). Corral-Verdugo et al. (2016) explicitly refer to SDT to explain how sustainable behaviours, such as frugality and equity, are mainly determined by intrinsic motivational drivers, for example self-efficacy, satisfaction and autonomy.

Although volunteering is driven by pro-social motivation, many authors have stressed intrinsic motivation can also be in place for workers supplying unpaid labour. Cappellari and Turati (2004), Carpenter and Myers (2010), Cappellari et al. (2011) and Bruno and Fiorillo (2012) explicitly introduce intrinsic motivation as a variable influencing volunteers' behavior. Meier and Stutzer (2008) identify three categories of motivation for volunteers: (1) the benefit from intrinsic work enjoyment; (2) the warm glow described by Andreoni (1990) and (3) social preferences.

\subsection{Measurements}

\subsubsection{Self-assessed Motivation}

Feldman and Perez (2012) measured environmental commitment, pro-environmental behavior and willingness to bear personal costs for recycling using three questions concerning people's attitudes towards the environment. Although they refer to these categories as intrinsically motivated, no direct relationship with self-efficacy, autonomy or the feeling of competence appears in the questions proposed. In the nine studies reported by De Young (2000), the types of motivation are rated on a five-point Likert scale. Jakovcevic et al (2014) used a questionnaire to classify the motivation for using own shopping bags, distinguishing between pro-environmental and economic reasons. Corral-Verdugo et al. (2016) used three different scales for self-efficacy, satisfaction and autonomy. Dedeurwaerdere et al. (2016) analysed a survey of 34 highly successful and prominent biodiversity arrangements in seven EU countries. The authors used as a proxy for intrinsic motivation the answers to a question concerning economic benefits derived from participation in biodiversity arrangements, labelling those not motivated by economic benefits "non-economically motivated".

Carpenter and Myers (2010) measured the altruism of volunteers based on the experimental results of a dictator game. Meier and Stutzer (2008) analysed the relationship between life satisfaction and volunteering, measuring intrinsic motivation in terms of the relative importance people assign to intrinsic goals (family and friends) compared to extrinsic goals (career and income). Bruno and Fiorillo (2012) measured intrinsic motivation using responses to questions concerning motivation for volunteering.

\subsubsection{Inferred Motivation}

Cappellari et al. (2011) used attendance at religious services as a proxy for altruism and the warm glow finding a significant impact on time donations. 


\subsection{Motivation, Choices and Performance}

In a comparison of institutional arrangements for biodiversity programmes, Dedeurwaerdere et al. (2016) found the participation of non-economically motivated individuals to be highly correlated with a governance variable conducive to a sense of autonomous self-determination by the participants (p. 7). Non-economically motivated individuals may include both intrinsically motivated and pro-socially motivated individuals.

In their study on plastic bag use, Jakovcevic et al. (2014) found that the prevalent motivation for carrying own bags is to protect the environment, followed by convenience and - less importantly - financial motives. Frugality and equity are significantly related to intrinsic motives because the more a person reported engaging in a reduced-consumption lifestyle and treating others in a fair and unbiased way, the more he/she reported feelings of autonomy, self-efficacy and satisfaction (Corral-Verdugo et al., 2016). According to de Young (2000), an individual who frequently engages in sustainable practices experiences an intrinsic satisfaction from his/her pro-environmental competency. Bolderdijk et al. (2012) show that biospheric concerns provide a better explanation of behavioral change in promoting energy conservation than economic concerns.

Meier and Stutzer (2008) and Bruno and Fiorillo (2012) found that both intrinsic and extrinsic motivation explain unpaid labour supply. Cappellari et al. (2011) and Carpenter and Myers (2010) show a positive relationship between pro-social motivation and the probability of engaging in time donation.

\subsection{Motivation and Incentives}

\subsubsection{Crowding Out}

Rommel et al. (2015) found no evidence of a motivation crowding-out effect for monitoring and small rewards in pro-environmental behavior, but their experiment did not check the initial pro-environmental motivation of participants. Feldman and Perez (2012) compared the effects of three regulatory techniques to encourage recycling activity, finding that willingness to bear personal costs for recycling (measured by the distance one must walk to the recycling point) can be affected by a crowding-out effect.

In a general framework of effort supply, Heyman and Ariely (2004) tested the relationship between effort and payments, showing that when the market is perceived as "social", effort is indifferent to the magnitude of rewards, whereas money markets are characterized by a monotonic relationship between payment and effort. Although the authors measured performance rather than motivation, they conclude that social rewards do not undermine intrinsic motivation. The experimental design suggests that what is being tested is a crowding-out hypothesis rather than an undermining situation. Ariely et al. (2009b) did not measure motivation, but concluded that high reward levels had a detrimental effect on performance.

\section{Some cross-cutting Themes}

\subsection{Legal Enforcement and Crowding Out}

The relationship between motivation and performance can be strongly influenced by the legal framework and the specific arrangements employed. According to Feldman and Teichman (2008), different legal regimes have different crowding-out effects on behavior with negative externalities: a payment imposed after the fact together with uncertainty induces an attenuated crowding-out effect compared to a regime that asks individuals to pay a certain amount up front to engage in a particular kind of behavior. The argument is that uncertain costs are viewed as a punishment, whereas certain advance payments create the belief that, the right to engage in undesirable behavior has been bought.

Another perspective concerns the description of legal directives as rules or as standards, with bright-line rules giving clear instructions to individuals, whereas standards are more abstract (Atiq, 2014). This can be relevant for situations in which intrinsic motivation plays a prominent role in human behavior. Atiq (2014) investigated the role of intrinsic motivation in relation to several issues: patent protection of laws of nature, natural phenomena and abstract ideas; the unenforceability of donative promises; the declining popularity of heart-balm laws. He argues that "when extrinsic legal considerations become a person's reasons for acting, they deprive her of the experience of desiring personal achievement, knowledge, general welfare for their own sake - an experience that, as noted, is crucial to the fortification of intrinsic motivation" (p. 1089). Consequently, in making a comparison between standards and bright-line rules, standards have the advantage of mitigating the crowding-out effect in situations in which intrinsic motivation plays a role because they often incorporate moral concepts in legal prescription.

\subsection{Neuroscience}

An interesting issue is the neural basis for the undermining effect of extrinsic incentives. Murayama et al. (2010) 
lend support for the undermining effect being closely linked to a decreased sense of self-determination. They show that after the removal of rewards, people do not experience a subjective value in succeeding in the task (decrease in the activation of the striatum and midbrain) and they are not motivated to show engagement (decrease in the lateral prefrontal cortex). Legault and Inzlicht (2012) measured individuals' autonomy before neurophysiological recording to test SDT. The authors found that autonomy is positively associated with self-regulatory performance and that when autonomous motivation is contextually supported, task performance increases. In a recent review, Botvinick and Braver (2015) accorded neuroscience a fundamental role in explaining the interaction between motivation and cognitive control.

\subsection{Creativity and Incentives}

Creativity is a fundamental element in many of the fields investigated above. It plays a role in information technology, in academic research and in entrepreneurship. However, it is a minor theme of investigation within some disciplines. In economics, very little attention has been paid to the relationship between incentive and creativity. Charness and Grieco (2013) tested the effects of financial incentives in stimulating creativity using two different arrangements. They show that financial incentives promote creativity when it must be exerted in a constrained framework, with the creative use of a given number of items, whereas incentives do not facilitate unconstrained creativity. Empirical studies have found conflicting results concerning the relationship between intrinsic motivation and creativity (Grant \& Berry, 2011). Gibbs et al. (2015) consider that their experiment demonstrates no motivational crowding-out effect, suggesting that rewards increased creativity among employees participating in a suggestion system for ideas concerning product and process improvements. In the same field of employee organizations, Grant and Berry (2011) suggest that intrinsically motivated employees notice, encode and retain information that is consistent with their desires; however, to produce new ideas, they must perceive that ideas can also be useful to others. Specifically, employees channel their intrinsic motivation towards producing ideas when guided by prosocial motivations, thereby achieving higher creativity.

\section{Discussion}

\subsection{Measurements}

Table 1 collates the results from the literature, distinguishing between those results confirming the relevance of intrinsic motivation and those confirming pro-social motivation. Only direct assessments of motivation are included in this summary; results obtained with proxies or not derived from specific questions that could be related to one or another type of motivation are excluded.

Table 1. Intrinsic motivation vs pro-social motivation

\begin{tabular}{lll}
\hline Topic & Intrinsic & Pro-social \\
motivation & motivation
\end{tabular}




\begin{tabular}{|c|c|c|}
\hline & Wiklund et al. (2003) & \\
\hline & Corman et al. (1988) & \\
\hline & Lam (2011) & \\
\hline & Hayter (2011) & \\
\hline \multirow[t]{5}{*}{ Consumption } & Anghelcev (2015), & Poch and Martin (2014) \\
\hline & Kivetz (2003) & Hamari et al. (2015) \\
\hline & Koufaris (2002) & \\
\hline & Hamari et al. (2015) & \\
\hline & Grant (2008) & Grant (2008) \\
\hline \multirow{4}{*}{$\begin{array}{l}\text { Public } \\
\text { administration }\end{array}$} & & Bertelli (2006) \\
\hline & & Brewer and Selden (1998) \\
\hline & & Alonso and Lewis (2001) \\
\hline & & Liu et al. (2008) \\
\hline \multirow{5}{*}{$\begin{array}{l}\text { Environment } \\
\text { and volunteering }\end{array}$} & Corral-Verdugo et al. (2016) & Feldman and Perez (2012) \\
\hline & Bruno and Fiorillo (2012) & Jakovcevic et al (2014) \\
\hline & & Dedeurwaerdere et al. (2016) \\
\hline & & Meier and Stutzer (2008) \\
\hline & & Carpenter and Myers (2010) \\
\hline
\end{tabular}

A first look at the table shows that intrinsic motivation is found to be relevant in many areas of investigation; moreover, moving from the top to the bottom of the table, it appears that the emphasis shifts from intrinsic to pro-social motivation.

In each area of investigation, different behaviors are examined, differing substantially in their effects on social or others' welfare. Information technology, games and gamification seem to be ideal fields in which to test and verify how intrinsic motivation works and which tools better enhance intrinsic motivation. There is no question that developing software and new technology creates value for society as a whole, as well as innovations, but from the microeconomic perspective of the single user or developer, the contribution to the whole is negligible and hardly detectable, the externality effect being less relevant than involvement in the task itself. In terms of games and gamification, no externality takes place. Health and entrepreneurship also interesting areas for testing intrinsic motivation. These fields are strictly related to individual behavior (except blood donations) and self-interest. With the limits imposed on this review, the behaviors investigated in these areas cannot produce relevant positive externalities for other individuals.

Public administration, the environment and volunteering are, instead, strictly associated with collective welfare and prosocial motivation becomes more relevant than intrinsic motivation. Nevertheless, intrinsic motivation still has a role. Only Grant (2008) and Hamari et al. (2015) test both types of motivation in the same framework, suggesting that the reinforcement between the two may be relevant.

One can also observe that in these behaviors, from the microeconomic perspective of the single agent, the contribution to the whole is negligible; for example, saving the use of one plastic bag in the world is irrelevant for the environment. Why in this area is pro-social motivation more prominent, whereas for open source contributors the opposite occurs? To provide an answer to this question, a deeper distinction between how types of motivation are linked to tasks and goals is needed.

\subsection{The Task and the End}

When intrinsic motivation plays a role, the task in itself is significant for the individual. In economic terms, effort and time spent on the task is an argument of the utility function. The more engaged an individual is, the greater the satisfaction. There can be contributions to others' welfare, but these are unintended effects and can be analysed only as positive externalities. 


$$
U_{i}\left(x_{i}, e_{i}\right) ; U_{j}\left(x_{j}, e_{i}\right)
$$

In the case of pro-social motivation, the goal gives value to the performer. Effort and time spent on the task and their results have no direct effect on the individual's welfare, so engagement does not increase the utility function. The task is not the end, because the end is others' welfare. Only if a direct relationship between the task and others' welfare is established, will the task be performed. Thus:

$$
U_{i}\left(x_{i}, U_{j}\right) ; U_{j}\left(x_{j}, e_{i}\right)
$$

Clearly, sometimes different types of motivation can be mixed, for example, when a pro-social behavior is interesting in itself, or a task that is enjoyed produces welfare improvements for other individuals, but it is important to identify the prevalent driver.

From a policy perspective, interventions to promote desired behaviors will differ in terms of the objectives and instruments that need to be employed depending on the motivation. If intrinsic motivation prevails, the matter of concern is the effect of rewards and whether or not they undermine intrinsic motivation. Other interesting interventions relate to gamification, which can make dull tasks more interesting, or enhance behavior that brings about positive externalities. This can be a powerful instrument to promote behaviors that would otherwise be neglected.

To promote pro-social behaviors, the link between personal effort and others' welfare needs to be intensified, improving the efficacy of effort for others.

A final question concerns the relationship between behaviors in different areas. Should an open source developer be a blood donor? Should an activist for environmental issues be a volunteer? Houston (2006) investigated this issue, showing that government employees are more likely to volunteer for charity and to donate blood than for-profit employees are.

As a whole, the distinction between intrinsic and pro-social motivation plays a role in economic theory, not only because of the different objective functions to be taken into account when modelling the two. The existence of positive externalities generates pro-social motivation. The mixing of intrinsic and pro-social motivation can be a non-rigorous simplification, mostly through denying a role for enjoyment and psychological needs for autonomy and competence.

In this area, the investigation of new frontiers supplied by information technology is particularly powerful, presenting opportunities for the economics field to gain new instruments and evidence for analysing economic choices and behaviors. Gamification should be investigated by those interested in the effects of incentives to explore and detail how human beings react to incentives other than monetary.

\subsection{Motivation, Choices and Performance}

Both intrinsic and pro-social types of motivation have significant effects on individual performance (Table 2). This implies that desired behaviors can be promoted by enhancing motivation. The issue is how to enhance motivation. The relationship with incentives is addressed in the subsequent section; here, we can add insights by considering how performance is associated with individual satisfaction. When there is intrinsic motivation, the effort in itself is pleasant and the associated performance increases to the extent that motivation is enhanced by feelings of autonomy, competence and relatedness. In terms of the above utility functions, effort is the independent variable of two separate functions, the utility function and the production function: the relationship between effort and performance is irrelevant to the performer's pleasure. Formally:

$$
U_{i}\left(x_{i}, \alpha e_{i}\right) ; Y=g\left(e_{i}\right)
$$

Where $\alpha$ represents the multiplicative effect of self-determination.

When pro-social motivation becomes relevant, the relationship between effort and performance is more important to the performer because he/she is satisfied as the other's welfare improves. If his effort is effective in terms of performance and performance has a beneficial effect on others' welfare, the performer will have a strong interest in exerting more effort. Formally:

$$
U_{i}\left(x_{i}, U_{j}\right) ; U_{j}\left(x_{j}, \beta Y\right) ; Y=g\left(e_{i}\right)
$$

Where $\beta$ represents the effectiveness of performance in relation to the other's welfare.

The two different mechanisms have strong policy implications for those interested in higher performance. To support intrinsically motivated performance, autonomy, competence and relatedness should be enhanced; this is the ideal instrument as higher $Y$ is given by higher $\alpha$. On the other hand, pro-social behaviors can be promoted by strengthening the functional relationship between effort and performance (acting on the parameters of the 
production function $\mathrm{g}$ ) and between performance and others' welfare (the $\beta$ parameter). Healthy behaviors or game involvement can be supported by mechanisms highlighting autonomy and competence, whereas little effect will be associated with the higher welfare of other individuals. As shown in the review provided by $\mathrm{Ng}$ et al. (2012), gym attendance can be fostered by a climate supportive of autonomy, whereas external or controlling mechanisms can be counterproductive. No effect will be detected on performance from higher quality gym equipment (the production function) unless it enhances performer competence.

In terms of self-selection in specific tasks or activities, this seems to be a prominent issue for activities in which pro-social motivation plays a prevalent role (last rows in Table 2).

Table 2. Relationships between motivation, choices and performance

\begin{tabular}{|c|c|c|}
\hline Topic & $\begin{array}{l}\text { Positive relationship between motivation and } \\
\text { performance }\end{array}$ & $\begin{array}{l}\text { Positive relationship between motivation and } \\
\text { choices } \\
\text { (self-selection) }\end{array}$ \\
\hline \multirow{3}{*}{$\begin{array}{l}\text { Information } \\
\text { technology }\end{array}$} & Osterloth and Rota (2005), yes & \\
\hline & Hars and $\mathrm{Ou}(2005)$, yes & \\
\hline & Mehri (2016) & \\
\hline \multirow{6}{*}{ Health } & Wu and Liu (2007), yes & \\
\hline & Przybylski et al. (2010), yes & \\
\hline & $\mathrm{Ng}$ and colleagues (2012) & \\
\hline & Puente and Anshel (2010) & \\
\hline & Teixeira et al. (2012) & \\
\hline & $\begin{array}{l}\text { Pentecost et al. (2017), positive relationship with } \\
\text { intentions }\end{array}$ & \\
\hline \multirow[t]{2}{*}{ Entrepreneurship } & Iorio et al. (2017) & Cassar (2007), yes \\
\hline & Hayter (2011), yes & \\
\hline \multirow{3}{*}{ Consumption } & Lam (2011), yes & \\
\hline & Ahn et al. (2007) & \\
\hline & Koufaris (2002) & \\
\hline \multirow{6}{*}{$\begin{array}{l}\text { Public } \\
\text { administration }\end{array}$} & Poch and Martin (2014) & \\
\hline & Hamari et al. (2015), yes & \\
\hline & Grant (2008) & Gregg et al. (2011) yes \\
\hline & Bertelli (2006) & Georgellis et al. (2011), yes \\
\hline & & Delgaaw and Dur (2008), yes \\
\hline & & Perry (2000), yes \\
\hline \multirow{7}{*}{$\begin{array}{l}\text { Environment } \\
\text { and volunteering }\end{array}$} & Jakovcevic et al. (2014), yes PM & Dedeurwaerdere et al. (2016) \\
\hline & Corral-Verdugo et al. (2016), yes IM & Carpenter and Myers (2010), yes \\
\hline & Bolderdijk et al. (2012), yes PM & \\
\hline & de Young (2000) & \\
\hline & Meier and Stutzer (2008) & \\
\hline & Bruno and Fiorillo (2012), yes & \\
\hline & Cappellari et al. (2011), yes & \\
\hline
\end{tabular}




\subsection{Motivation and Incentives}

The theme debated in the literature of the perverse relationship between incentives and performance does not find great support in this review. In Table 3, we include studies that specifically tested undermining or crowding-out effects. First, it appears that many authors have sought the crowding-out effect, which is a variant of the undermining effect demonstrated in the psychological literature. In this extended interpretation of incentive functioning, little evidence has been collected outside psychology. The effect of undermined intrinsic motivation, once the reward was removed, remains the only tested effect. In relation to pro-social motivation, evidence is scarce and - above all - there is no theoretical explanation describing how crowding out or undermining should act. In SDT, a specific mechanism highlights that people must not only experience competence or efficacy, but must also experience their behavior as self-determined for intrinsic motivation to be evident. Motivation is undermined when a reward affects perceived self-determination, while the feeling of competence will not affect intrinsic motivation unless accompanied by a sense of autonomy (Deci \& Ryan, 2000, p. 70). "When individuals perceive that an external intervention reduces their self-determination, intrinsic motivation is substituted by external control... and the locus of control (Rotter, 1966) shifts from inside to outside" (Frey \& Jegen, 2001, p. 594). It is unclear how a similar mechanism should work on pro-social motivation, which has different goals and characteristics.

Table 3. Relationships between motivation and incentives

\begin{tabular}{|c|c|c|}
\hline Topic & Undermining & Crowding out \\
\hline $\begin{array}{l}\text { Information } \\
\text { technology }\end{array}$ & & Roberts et al. (2006), no \\
\hline \multirow[t]{5}{*}{ Health } & Cooke et al. (2011), no & Promberger and Marteau (2013), no \\
\hline & Chairness and Gneezy (2009), no & Niza et al. (2013), no \\
\hline & Jeffery (2012), no & Mellstrom and Johannesson (2008), yes \\
\hline & Goette and Stutzer (2008), no & Glynn et al. (2003), yes \\
\hline & & Lacetera et al. (2013), no \\
\hline Consumption & & Anghelcev (2015), yes \\
\hline Public & & Bertelli (2006), consistent with \\
\hline administration & & Franck and Rosenthal (2006), no \\
\hline Environment & & Rommel et al. (2015), no \\
\hline \multirow[t]{3}{*}{ and volunteering } & & Feldman and Perez (2012), yes \\
\hline & & Heyman and Ariely (2004), no \\
\hline & & Ariely et al. (2009), no \\
\hline
\end{tabular}

\section{References}

Ahn, T., Ryu, S., \& Han, I. (2007). The impact of Web quality and playfulness on user acceptance of online retailing. Information \& Management, 44(3), 263-275, https://doi.org/10.1016/j.im.2006.12.008

Alonso, P., \& Lewis, G. B. (2001). Public service motivation and job performance: Evidence from the federal sector. The American Review of Public Administration, 31(4), 363-380. https://doi.org/10.1177/02750740122064992

Andreoni, J. (1989). Giving with Impure Altruism: Applications to Charity and Ricardian Equivalence. Journal of Political Economy, 97(6), 1447-1458. https://doi.org/10.1086/261662

Anghelcev, G. (2015). Unintended effects of incentivizing consumers to recommend a favorite brand. Journal of Marketing Communications, 21(3), 210-223. https://doi.org/10.1080/13527266.2012.747980

Alexy, O., \& Leitner, M. (2011). A Fistful of Dollars: Are Financial Rewards a Suitable Management Practice for Distributed Models of Innovation? European Management Review, 8, 165-185. https://doi.org/10.1111/j.1740-4762.2011.01017.x

Ariely, D., Bracha, A., \& Meier, S. (2009a). Doing Good or Doing Well? Image Motivation and Monetary Incentives in Behaving Prosocially. American Economic Review, 99(1), 1-12. 
https://doi.org/10.1257/aer.99.1.544

Ariely, D., Gneezy, U., Loewenstein, G., \& Mazara, N. (2009b). Large Stakes and Big Mistakes. Review of Economic Studies, 76(2), 451-469. https://doi.org/10.1111/j.1467-937X.2009.00534.x

Atiq, E. H. (2014). Why Motives Matter: Reframing the Crowding Out Effect of Legal Incentives, The Yale Law Journal, 123(4), 1070-1116.

Bardi, F., Eckhardt, G., M. (2012). Access-Based Consumption: The Case of Car Sharing. Journal of Consumer Research, 39, 881-898. https://doi.org/10.1086/666376

Baranowski, T., Baranowski, J., Cullen, K. W., Marsh, T., Islam, N., Zakeri, I., Honess-Morreale, L., deMoor, C. (2003). Squire's Quest! Dietary Outcome Evaluation of a Multimedia Game,. American Journal of Preventive Medicine, 1(24), 52-61. https://doi.org/10.1016/S0749-3797(02)00570-6

Baranowski, T., Buday, R., Thompson, D. I., \& Baranowski, J. (2008). Playing for real: video games and stories for health-related behavior change. American journal of preventive medicine, 34(1), 74-82. https://doi.org/10.1016/j.amepre.2007.09.027

Bartle, R. A. (2004). Designing virtual worlds. Berkeley, CA: New Riders.

Bénabou, R., \& Tirole, J. (2003). Intrinsic and Extrinsic Motivation. Review of Economic Studies, 70, 489-520. https://doi.org/10.1111/1467-937X.00253

Bénabou, R., \& Tirole, J. (2006). Incentive and Prosocial Behavior. The American Economic Review, 96(5), 1652-1678. https://doi.org/10.1257/aer.96.5.1652

Benkler, Y. (2004). Sharing Nicely: On Shareable Goods and the Emergence of Sharing as a Modality of Economic Production. Yale Law Journal, 114, 394-419. https://doi.org/10.2307/4135731

Bertelli, A. M. (2006). Motivation Crowding and the Federal Civil Servant: Evidence from the U.S. Internal Revenue Service. International Public Management Journal, 9, 3-23. https://doi.org/10.1080/10967490600625191

Boyer, P. C., Dwenger, N., \& Rincke, J. (2016). Do norms on contribution behavior affect intrinsic motivation? Field-experimental evidence from Germany. Journal of Public Economics, 144, 140-153. https://doi.org/10.1016/j.jpubeco.2016.10.003

Bolderdijk, J. W., Steg, L., Geller, E. S., Lehman, P. K., \& Postmes T. (2013). Comparing the effectiveness of monetary versus moral motives in environmental campaigning, Nature Climate Change, 3, 413-416. https://doi.org/10.1038/nclimate1767

Botvinick, M., \& Braver, T. (2015). Motivation and cognitive control: from behavior to neural mechanism. Annual Review of Psychology, 66, 83-113. https://doi.org/10.1146/annurev-psych-010814-015044

Bowles, S., \& Polania-Reyes, S. (2012). Economic Incentives and Social Preferences: Substitutes or Complements? Journal of Economic Literature, 50(2), 368-425. https://doi.org/10.1257/jel.50.2.368

Brewer, G. A., \& Selden, S. C. (1998). Whistle blowers in the federal civil service: New evidence of the public service ethic. Journal of Public Administration Research \& Theory, 8(3), 413-440. https://doi.org/10.1093/oxfordjournals.jpart.a024390

Bruno, B. (2014). Reconciling economics and psychology on intrinsic motivation. Journal of Neuroscience, Psychology and Economics, 6(2), 136-149. https://doi.org/10.1037/npe0000006

Bruno, B., \& Faggini, M. (2016). Sharing economy: for an economic taxonomy, International Joutrnal of Economics and Finance, 9(6), 174-178. https://doi.org/10.5539/ijef.v9n6p174

Budhathoki, N. R., \& Haythornthwaite, C. (2013). Motivation for open collaboration: Crowd and community models and the case of Open Street Map. American Behavioral Scientist, 57(5), 548-575. https://doi.org/10.1177/0002764212469364

Cahill, K., \& Perera, R. (2011). Competions and incentives for smoking cessation, Cochrane Database of Systematic Reviews, Issue 4. Art. No.: CD004307. https://doi.org/10.1002/14651858.CD004307.pub4

Cameron, J., \& Pierce, W. D. (1994). Reinforcement, reward, and intrinsic motivation: A meta-analysis. Review of Educational Research, 64, 363-423. https://doi.org/10.3102/00346543064003363

Carpenter, D. A. (2013). Open Source Software Volunteerism vs. Motivating Potential of Primary Employment: Suggestions for a Research Agenda, Journal of Information Systems Applied Research, 6(2), 22-30. 
Cassar, G. (2007). Money, money, money: A longitudinal investigation of entrepreneur career reasons, growth preferences and achieved growth. Entrepreneurship and Regional Development, 19. https://doi.org/10.1080/08985620601002246

Charness, G., \& Gneezy, U. (2009). Incentive to Exercise. Econometrica, 77(3), 909-931. https://doi.org/10.3982/ECTA7416

Charness, G., \& Grieco, D. (2013). Individual creativity, ex-ante goals and financial incentives, Departmental working papers, UCSB, UC Santa Barbara.

Chiu, C. M., Wang, E. T. G., Fang, Y. H., \& Huang, H. Y. (2014). Understanding customers' repeat purchase intentions in $\mathrm{B} 2 \mathrm{C}$ e-commerce: the roles of utilitarian value, hedonic value and perceived risk. Information Systems Journal, 24, 85-114. https://doi.org/10.1111/j.1365-2575.2012.00407.x

Chu, H. (2013). A conceptual model of motivations for consumer resale on $\mathrm{C} 2 \mathrm{C}$ websites. The Service Industries Journal, 33(15-16), 1527-1543. https://doi.org/10.1080/02642069.2011.636422

Cooke, L. J., Chambers L. C., Anez, E. V., Croker, H. A., Boniface, D., Yeomans, M. R., \& Wardle, J. (2011). Eating for pleasure or profit: The effect of incentives on children's enjoyment of vegetables. Psychological Science, 22(2), 190-196. https://doi.org/10.1177/0956797610394662

Corman, J., Perles, B., \& Vancini, P. (1988). Motivational factors influencing high-technology entrepreneurship. Journal of Small Business Management.

Corral-Verdugo V., Gonzales-Lomeli, D., Rascon-Cruz, M., \& Corral-Frias, V. O. (2016). Intrinsic Motives of Autonomy, Self-Efficacy, and Satisfaction Associated with Two Instances of Sustainable Behavior: Frugality and Equity, Psychology, 7, 662-671. https://doi.org/10.4236/psych.2016.75068

Crewson, P. (1997). Public-service motivation: Building empirical evidence of incidence. Journal of Public Administration Research \& Theory, 7(4), 499-519. https://doi.org/10.1093/oxfordjournals.jpart.a024363

Deci, E. L. (1971). Effects of externally mediated rewards on intrinsic motivation. Journal of Personality and Social Psychology, 18, 105-115. https://doi.org/10.1037/h0030644

Deci, E. L., Koestner, R., \& Ryan, R. M. (1999). A Meta-Analytic Review of Experiments Examining the Effects of Extrinsic Rewards on Intrinsic Motivation, Psychological Bulletin, 125(6), 627-668. https://doi.org/10.1037/0033-2909.125.6.627

Deci, E. L., \& Ryan, R. M. (1985). The general causality orientations scale: Self-determination in personality. Journal of research in personality, 19(2), 109-134. https://doi.org/10.1016/0092-6566(85)90023-6

Deci, E. L., \& Ryan, R. M. (2000). Intrinsic and Extrinsic Motivations: Classic Definitions and New Directions. Contemporary Educational Psychology, 25, 54-67. https://doi.org/10.1006/ceps.1999.1020

Deci, E. L., \& Ryan, R. M. (2016). Facilitating and Hindering Motivation, Learning and Well-being in schools. In Wentzel, K. R., Miele, D. B., (Eds.), Handbook of Motivation at School. New York: Routledge.

Delfgaauw, J., \& Dur, R. (2008). Incentives and workers' motivation in the public sector. The Economic Journal, 118, 171-191. https://doi.org/10.1111/j.1468-0297.2007.02108.x

Della Vigna, S., \& Malmendier, U. (2006). Paying Not to Go to the Gym, American Economic Review, 96(3), 694-719. https://doi.org/10.1257/aer.96.3.694

Deterding, S., Dixon, D., Khaled, R., \& Nacke, L. (2011). From game design elements to gamefulness: defining gamification. In Proceedings of the 15th International Academic MindTrek Conference: Envisioning Future Media Environments, September 28-30, 2011, Tampere, Finland, ACM, pp. 9-15.

De Young, R. (2000). New Ways to Promote Proenvironmental Behavior: Expanding and Evaluating Motives for Environmentally Responsible Behavior. Journal of Social Issues, 56, 509-526. https://doi.org/10.1111/0022-4537.00181

Fehr, E., \& Fischbacher, U. (2002). Why social preferences matter-the impact of non-selfish motives on competition, cooperation and incentives. The Economic Journal, 112(478), C1-C33. https://doi.org/10.1111/1468-0297.00027

Feldman, Y., \& Perez, O. (2012). Motivating Environmental Action in a Pluralistic Regulatory Environment: An Experimental Study of Framing, Crowding Out, and Institutional Effects in the Context of Recycling Policies, Law \& Society Review, 46(2), 405-442. https://doi.org/10.1111/j.1540-5893.2012.00493.x

Feldman, Y., \& Techman, D. (2008). Are all "legal dollars" created equal? Northwestern University Law Review, 
102(1), 223-262. https://doi.org/10.2139/ssrn.963202

Festré, A., \& Garrouste, P. (2008). Motivation, incentives and performance in the public sector. Paris: Centre d'économie de la Sorbonne (CES).

Festré, A., \& Garrouste, P. (2015). Theory and evidence in psychology and economics about motivation crowding out: A possible convergence? Journal of Economic Surveys, 29(2), 339-356. https://doi.org/10.1111/joes.12059

Frank, R. G., \& Rosenthal, M. B. (2006). What Is the Empirical Basis for Paying for Quality in Health Care? Medicale Care Research Review, 63(2), 135-157. https://doi.org/10.1177/1077558705285291

Frey, B. S., \& Jegen, R. (2001). Motivation Crowding Theory: A Survey of Empirical Evidence. Journal of Economic Surveys, 15(5), 589-611. https://doi.org/10.1111/1467-6419.00150

Geller, E. S. (1989). Applied behavior analysis and social marketing: An integration for environmental preservation. Journal of Social Issues, 45, 17-36. https://doi.org/10.1111/j.1540-4560.1989.tb01531.x

Georgellis, Y., Iossa, E., \& Tabvuma, V. (2011). Crowding Out Intrinsic Motivation in the Public Sector, Journal of Public Administration Research Theory, 21(3), 473-493. https://doi.org/10.1093/jopart/muq073

Gibbs, M., Neckermann, S., \& Siemroth, C. (2014). A field experiment in motivating employee ideas. Review of Economics and Statistics.

Glynn, S. A., Kleinman, J., Schreiber, G. B., Zuck, T., Mc Combs, S., Bethel, J., Garratty, G., \& Williams, A. E., (2002). Motivations to donate blood: demographic comparisons, Transfusion, 42(2), 216-225. https://doi.org/10.1046/j.1537-2995.2002.00008.x

Glynn, S. A., Williams, A. E., Nass, C. C., Bethel, J., Kessler, D., Scott, E. P., Fridey, J., Kleinman, S. H., \& Schreiber G. B. (2003). Attitudes toward blood donation incentives in the United States: implications for donor recruitment. Transfusion, 43(1), 7-16. https://doi.org/10.1046/j.1537-2995.2003.00252.x

Goette, L., \& Stutzer, A. (2008). Blood donations and incentives: evidence from a field experiment. IZA Working paper no. 3580.

Goette, L., Stutzer, A., \& Frey, B. M. (2010). Prosocial Motivation and Blood Donations: A Survey of the Empirical Literature. Transfusion Medicine and Hemotherapy, 37, 149-154. https://doi.org/10.1159/000314737

Grant, A. (2008). Does Intrinsic Motivation Fuel the Prosocial Fire? Motivational Synergy in Predicting Persistence, Performance, and productivity. Journal of Applied Psyhology, 93(1), 48-58. https://doi.org/10.1037/0021-9010.93.1.48

Grant, A., Berry, J. W., 2011. The Necessity of Others is The Mother of Invention: Intrinsic and Prosocial Motivations, Perspective Taking, and Creativity, The Academy of Management Journal 54(1):73-96. https://doi.org/10.5465/AMJ.2011.59215085

Gregg, P., Grout, P. A., Ratcliffe, A., Smith, S., \& Windmeijer, F. (2011). How important is pro-social behavior in the delivery of public services? Journal of Public Economics, 95(7-8), 758-766. https://doi.org/10.1016/j.jpubeco.2011.03.002

Hagstrom, W. O. (1965). The Scientific Community. Basic Books, New York.

Hamari, J., Koivisto, J., \& Sarsa, H. (2014). Does gamification work? - A literature review of empirical studies on gamification. In proceedings of the 47th Annual Hawaii International Conference on System Sciences, Hawaii, USA, January 6-9, 2014. https://doi.org/10.1109/HICSS.2014.377

Hamari, J., Sjoklint, M., \& Ukkonen, A. (2015). The Sharing Economy: Why people Particpate in Collaborative Consumption, Journal of the Association for Information Science and Technology. https://doi.org/10.1002/asi.23552

Hars, A., \& Ou, S. (2005). Working for free? - Motivations of participating in Opens Source Projects. International Journal of Electronic Commerce, 6, 25-39.

Hayter, C. S. (2011). In search of the profit-maximizing actor: motivations and definitions of success from nascent academic entrepreneurs. The Journal of Technology Transfer, 36(3), 340-352. https://doi.org/10.1007/s10961-010-9196-1

Hessels, J., Van Gelderen, M., \& Thurik, R. (2008). Entrepreneurial aspirations, motivations, and their drivers. Small Business Economics, 31, 323-339. https://doi.org/10.1007/s11187-008-9134-X 
Heyman, J., \& Ariely, D. (2004). Effort for Payment, Psychological Science, 15(11), 787-793. https://doi.org/10.1111/j.0956-7976.2004.00757.x

Houston, D. J. (2000). Public-Service Motivation: A Multivariate Test. Journal of Public Administration Research \& Theory, 10(4), 713-728. https://doi.org/10.1093/oxfordjournals.jpart.a024288

Houston, D. J. (2006). "Walking the walk" of public service motivation: public employees and charitable gifts of time, blood, and money. Journal of Public Administration Research and Theory, 16(1), 67-86. https://doi.org/10.1093/jopart/mui028

Huotari, K., \& Hamari, J. (2011). "Gamification" from the perspective of service marketing. Proc. CHI 2011 Workshop Gamification.

Jakovcevic, A., Steg, L., Mazzeo, N., Caballero, R., Franco, P., Putrino, N., \& Favara, J. （2014） . Charges for plastic bags: Motivational and behavioral effects, Journal of Environmental Psychology, 40, 372-380. https://doi.org/10.1016/j.jenvp.2014.09.004

Jeffery, R. W. (2012). Financial incentives and weight control, Preventive Medicine, 55, S61-S67. https://doi.org/10.1016/j.ypmed.2011.12.024

Kim, S. (2005). Individual-level factors and organizational performance in government organizations, Journal of Public Administration Research and Theory, 15(2), 245-261. https://doi.org/10.1093/jopart/mui013

Kivetz, R. (2003). The Effects of Effort and Intrinsic Motivation on Risky Choice, Marketing Science, 22(4), 477-502. https://doi.org/10.1287/mksc.22.4.477.24911

Koufaris, M. (2002). Applying the Technology Acceptance Model and Flow Theory to Online Consumer Behavior, Information System Research, 13(2), 205-223. https://doi.org/10.1287/isre.13.2.205.83

Kuratko, D., Hornsby, J., \& Naffziger, D. (1997). An Examination of Owner's Goals in Sustaining Entrepreneurship. Journal of Small Business Management, 35(1), 24-33.

Lacetera, N., Macis, N., \& Slonim, R. (2013). Public health. Economic rewards to motivate blood donations, Science (New York, N.Y.), 340(6135), 927-928. https://doi.org/10.1126/science.1232280

Lakhani, K. R., \& Wolf, R. G. (2003). Why hackers do what they do: Understanding motivation effort in free/open source software projects. (2003) . Working Paper 4425-03, Sloan School of Management, MIT, Cambridge, MA.

Lam, A. (2011). What motivates academic scientists to engage in research commercialization:'Gold', 'ribbon'or 'puzzle'? Research policy, 40(10), 1354-1368. https://doi.org/10.1016/j.respol.2011.09.002

Legault, L., \& Inzlicht, M. (2013). Self-determination, self-regulation, and the brain: Autonomy improves performance by enhancing neuroaffective responsiveness to self-regulation failure. Journal of Personality and Social Psychology, 105(1), 123. https://doi.org/10.1037/a0030426

Lerner, J., \& Tirole, J. (2002). Some Simple Economics of Open Source. The Journal of Industrial Economics, 50(2), 197-234. https://doi.org/10.1111/1467-6451.00174

Liu, B., Tang, N., \& Zhu, X. (2008). Public service motivation and job satisfaction in China: An investigation of generalisability and instrumentality. International Journal of Manpower, 29(8), 684-699. https://doi.org/10.1108/01437720810919297

Lyons, S. T., Duxbury, L. E., \& Higgins, C. A. (2006). A Comparison of the Values and Commitment of Private Sector, Public Sector, and Parapublic Sector Employees. Public Administration Review, 66(4), 605-618. https://doi.org/10.1111/j.1540-6210.2006.00620.x

Mathwick, C., Malhotra, N., \& Rigdon, E. (2001) Experiential value: conceptualization, measurement and application in the catalog and internet shopping. Journal of Retailing, 77, 39-56. https://doi.org/10.1016/S0022-4359(00)00045-2

Mellstrom, C., \& Johannesson, M. (2008). Crowding out in blood donation: was Titmuss right? Journal of the European Economic Association, 6(4), 845-863. https://doi.org/10.1162/JEEA.2008.6.4.845

Mekler, E., Brühlmann, F., Opwis, K., \& Tuch, A., (2013). Disassembling gamification: the effects of points and meaning on user motivation and performance. In CHI '13 extended abstracts on human factors in computing systems, 1137-1142. https://doi.org/10.1145/2468356.2468559

Mehri, M. I. (2016). Towards a framework for online game adoption Computers in Human Behavior. https://doi.org/10.1016/j.chb.2016.02.072 
Merton, R. (1957). Priorities in scientific discovery: A chapter in the sociology of science. American Sociological Review, 22(6), 635-659. https://doi.org/10.2307/2089193

Merton, R. K. (1973). The Sociology of science: Theoretical and Empirical Investigations. University of Chicago Press, Chicago.

Murayama, K., Matsumoto, M., Keise, I., \& Matsumoto, K. (2010). Neural basis of the undermining effect of monetary reward on intrinsic motivation. Proceedings of the National Academy of Sciences of the United States of America, 107(49), 20911-20916. https://doi.org/10.1073/pnas.1013305107

Ng, J. Y., Ntoumanis, N., Th.gersen-Ntoumani, C., Deci, E. L., Ryan, R. M., Duda, J. L., \& Williams, G. C. (2012). Self-Determination Theory Applied to Health Contexts: A Meta-Analysis. Perspectives on Psychological Science, 7(4), 325-340. https://doi.org/10.1177/1745691612447309

Niza, C., Tung, B., \& Martea, T. M. (2013). Incentivizing Blood Donations: Systematic Review an MetaAnalysis to Test Titmuss' Hypotheses. Health Psychology, 32(9), 941-949. https://doi.org/10.1037/a0032740

Osterloh, M., \& Rota, S. (2007). Open source software development—Just another case of collective invention? Research Policy, 36(2), 157-171. https://doi.org/10.1016/j.respol.2006.10.004

Pais, I., \& Provasi, G. (2015). Sharing Economy: A Step towards the Re-Embeddedness of the Economy? Stato e Mercato, 3, 347-377.

Park, S. M., Min, K. R., \& Chen, C. A. (2016). Do monetary rewards bring happiness? Comparing the impacts of pay-for-performance in the public and private sectors. International Review of Public Administration, 21(3), 199-215. https://doi.org/10.1080/12294659.2016.1237092

Pentecost, R., \& Denni, A. S. T. (2017). It's my choice! Investigating barriers to pro-social blood donating behavior. Marketing Intelligence \& Planning, 35(2). https://doi.org/10.1108/MIP-03-2016-0055

Perry, J. L., Hondenghem, A., \& Wise, L. R. (2010). Revisiting the Motivational Bases of Public Service: Twenty Years of Research and an Agenda for the Future. Public Administration Review, 70(5), 681-690. https://doi.org/10.1111/j.1540-6210.2010.02196.x

Perry, J. L., \& Wise, L. R. (1990). The Motivational Bases of Public Service. Public Administration Review, 50(3), 367-73. https://doi.org/10.2307/976618

Petty, R., \& Cacioppo, J. (2012). Communication and persuasion: Central and peripheral routes to attitude change. Springer Science \& Business Media.

Poch, R., \& Martin, B. (2015). Effects of intrinsic and extrinsic motivation on user-generated content. Journal of Strategic Marketing, 23(4), 305-317. https://doi.org/10.1080/0965254X.2014.926966

Promberer, M., \& Marteau T. M. (2013). When Do Financial Incentives Reduce Intrinsic Motivation? Comparing Behaviors Studied in Psychological and Economic Literature. Health Psychology, 32(9), 950-957. https://doi.org/10.1037/a0032727

Prothero, A., Dobscha, S., Freund, J., Kilbourne, W. E., Luchs, M. G., Ozanne, L. K., \& Thøgersen, J. (2011). Sustainable consumption: Opportunities for consumer research and public policy. Journal of Public Policy \& Marketing, 30(1), 31-38. https://doi.org/10.1509/jppm.30.1.31

Przybylski, A. K., Rigby, C. S., \& Ryan, R. M. (2010). A motivational model of video game engagement. Review of General Psychology, 14(2), 154-166. https://doi.org/10.1037/a0019440

Puente, R., \& Anshel, M. H. (2010). Exercisers' perceptions of their fitness instructor's interacting style, perceived competence, and autonomy as a function of self-determined regulation to exercise, enjoyment, affect, and exercise frequency. Scandinavian journal of psychology, 51(1), 38-45. https://doi.org/10.1111/j.1467-9450.2009.00723.x

Ritz, A., Brewer, G. A., \& Neumann, O. (2016). Public service motivation: A systematic literature review and outlook. Public Administration Review. https://doi.org/10.1111/puar.12505

Ryan, R. M., Connel, J. P., 1989. Perceived locus of causality and internalization: Examining reasons for acting in two domains. Journal of Personality and Social Psychology, 57(5), 749-761. https://doi.org/10.1037/0022-3514.57.5.749

Ryan, R. M., \& Deci, E. L. (2000). Self Determination Theory and the Facilitation of Intrinsic Motivation, Social Development, and Well-Being. American Psychologist, 55, 68-78. 
https://doi.org/10.1037/0003-066X.55.1.68

Ryan, R. M., Rigby, C. S., \& Przybylski, A. (2006). The motivational pull of video games: A self-determination theory approach. Motivation and Emotion, 30, 347-364. https://doi.org/10.1007/s11031-006-9051-8

Rommel, J., Buttmann, V., Liebig, G., Schönwetter, S., \& Svart-Gröger, V. (2015). Motivation crowding theory and pro-environmental behavior: Experimental evidence. Economic Letters, 129, 42-44. https://doi.org/10.1016/j.econlet.2015.01.025

Roberts, J., Il-Horn, H., \& Slaughter, S. A. (2006). Understanding the Motivations, Participation, and Performance of Open Source Software Developers: A Longitudinal Study of the Apache Projects, Management Science, 52(7), 984-999. https://doi.org/10.1287/mnsc.1060.0554

Rotter, J. B. (1966). Generalised expectancies for internal versus external control of reinforcement, Psychological Monographs, 80(1).

Tamborini, R., Bowman, N. D., Eden, A., Grizzard, M., \& Organ, A. (2010). Defining media enjoyment as the satisfaction of intrinsic needs. Journal of Communication, 60(4), 758-777. https://doi.org/10.1111/j.1460-2466.2010.01513.x

Teixeira, P. J., Carraça, E. V., Markland, D., Silva, M. N., \& Ryan, R. M. (2012). Exercise, physical activity, and self-determination theory: A systematic review. International Journal of Behavioral Nutrition and Physical Activity, 9(1), 78. https://doi.org/10.1186/1479-5868-9-78

Upton, W. E. (1973). Altruism, Attribution, and Intrinsic Motivation in the Recruitment of Blood Donors. Dissertation, Cornell University.

Vandenabeele, W. (2007). Toward a public administration theory of public service motivation: An institutional approach. Public Management Review, 9(4), 545-556. https://doi.org/10.1080/14719030701726697

Von Krogh, G., Haefliger, S., Spaeth, S., \& Wallin, M. (2012). Carrots and Rainbows: Motivation and Social Practice in Open Source Software Development, MIS Quarterly, 3.

Wiklund, J., Davidsson, P., \& Delmar, F. (2003). What do they think and feel about growth? An expectancy-value approach to small business managers' attitudes toward growth. Entrepreneurship Theory and Practice, 247-270. https://doi.org/10.1111/1540-8520.t01-1-00003

Wolfinbarger, M., \& Gilly, M. C. (2001). Shopping online for freedom, control, and fun. California Management Review, 43(2), 34-55. https://doi.org/10.2307/41166074

Wu, J., \& Liu, D. (nd.). The Effect of Trust and Enjoyment on Intention to Play Online Games, Journal of Electronic Commerce Research, 8(2), 128-140.

Yee, N. (2006b). Motivations for play in online games. Cyber Psychology \& Behavior, 9, 772-775. https://doi.org/10.1089/cpb.2006.9.772

\section{Copyrights}

Copyright for this article is retained by the author(s), with first publication rights granted to the journal.

This is an open-access article distributed under the terms and conditions of the Creative Commons Attribution license (http://creativecommons.org/licenses/by/4.0/). 